\title{
Pectinolytic, Indole-Positive Strains of Klebsiella pneumoniae
}

\author{
V. LYLE VON RIESEN \\ Department of Medical Microbiology, University of Nebraska Medical Center, Omaha, Nebraska 68105
}

The digestion of polypectate by each of the 11 indole-positive strains of Klebsiella pneumoniae studied is reported. The possible significance of pectinolytic activity for the identification of indole-positive strains of $K$. pneumoniae, the so-called "Oxytocum" group, is discussed.

A number of investigations have recently been reported on the systematics and differential diagnosis of the genus Klebsiella, with emphasis on the "Oxytocum," or indole-positive, strains of $K$. pneumoniae $(1,2,8,14,16)$. Over the years, from MacConkey (12) to Lautrop (11) to Hugh (7) to Stenzel et al. (16), the combination of gelatin liquefaction and indole formation has been used to identify members of the "Oxytocum" group; however, the gelatin reactions of these strains in stab cultures may be considerably delayed, as much as 4 to 11 weeks (11). In this paper is reported a characteristic, pectinolysis, which is more rapidly determined, more consistently produced, and taxonomically more significant than gelatin liquefaction for the identification of the indole-positive strains of $K$. pneumoniae.

\section{MATERIALS AND METHODS}

Bacterial strains. In a study designed to identify the strains of Enterobacter agglomerans in a group of nosocomial bacterial isolates (Ned Therien, M.S. thesis, Univ. of Nebraska Medical Center, Omaha, 1974), an indole-positive strain of $K$. pneumoniae was included as a reference strain for a computerized comparison. This strain was found to digest sodium polypectate (polygalacturonate, sodium salt, no. P-1879, Sigma Chemical Co., St. Louis, Mo.). Six additional indole-positive strains of $K$. pneumoniae were found in our departmental collection, and, subsequently, four more were obtained from the Medical Center Diagnostic Bacteriology Laboratory. Of these 11 strains, 5 are of human origin, 1 was isolated from a spoiled potato, and 5 were isolated from the hospital environment. When they were patched onto the surface of polypectate medium $(6,15,17)$ in petri dishes, all 11 strains developed depressions beneath and surrounding the growth within $24 \mathrm{~h}$.

Biochemical studies. Since pectinolytic activity is uncommon in the family Enterobacteriaceae $(4,6)$, it was decided to characterize fully these indole-positive klebsiellas to establish positively their identity. Eight of these strains, plus an indole-negative strain of $K$. pneumoniae, were reexamined during one time period by three approaches: (i) Enterotube and ENCISE II (Roche Diagnostics, Nutley, N.J.), (ii) API 20 Enteric and API Profile Register (Analytab Products Inc., Plainview, N.Y.), (iii) and con- ventional methods. The methods for performing the Enterotube and API 20 Enteric tests were those recommended by the manufacturers. Three indolepositive strains were obtained from the Medical Center Diagnostic Bacteriology Laboratory after the Enterotube and API 20 Enteric studies were made, and those were therefore examined only by the conventional methods.

The majority of the conventional tests used were performed with accepted commercial media according to the instructions and recommendations of the manufacturers. All of the basal and complete media used were products of Difco Laboratories, Detroit, Mich., except Trypticase soy agar and deoxyribonuclease (DNase) agar, which were from Baltimore Biological Laboratories, Cockeysville, Md. The procedures used were essentially those described in the Manual of Clinical Microbiology $(13,17)$. The tests and the media used were as follows: indole production $2 \%$ tryptone plus $0.5 \% \mathrm{NaCl}$ with Kovacs reagent), methyl red and Voges-Proskauer (MR-VP medium), citrate utilization (Simmons citrate agar), hydrogen sulfide production (Kligler iron agar), urease (urea agar base), motility and nitrate reduction (motility medium S), lysine decarboxylase and deaminase (lysine iron agar), arginine dihydrolase and ornithine decarboxylase (1\% amino acid in Moeller decarboxylase base plus $0.3 \%$ agar), phenylalanine deaminase (phenylalanine agar), malonate utilization (malonate broth), $o$-nitrophenyl- $\beta$-D-galactopyranoside (ONPG) hydrolysis (differentiation disks ONPG), acid from carbohydrates (1\% carbohydrate in phenol red broth base), DNase (DNase agar plus $0.01 \%$ toluidine blue $\mathrm{O}$ ), and chitinase $(0.25 \%$ sulfuric acid-dissolved chitin in Trypticase soy agar). Hydrolysis of Tween 80, Tween 85, lecithin, gelatin, casein, amylopectin, and esculin was evaluated as described by von Riesen (18). Final examinations for ornithine decarboxylase and arginine dihydrolase were made at 4 days, those for chitin hydrolysis were made at $72 \mathrm{~h}$, those for gelatin hydrolysis were made at 48 and $120 \mathrm{~h}$, and those for starch and casein hydrolysis were made at $48 \mathrm{~h}$; all other results were determined at $24 \mathrm{~h}$. All incubation was at $37 \mathrm{C}$.

\section{RESULTS}

ENCISE II identified the nine strains studied with Enterotube (11 reactions) as $K$. pneumoniae. Using the more extensive results (20 
to 22 reactions) from the API 20 Enteric, the API Profile Register identified the eight indolepositive strains as $K$. pneumoniae, Oxytocum group; the indole-negative control strain was identified as belonging to $K$. pneumoniae .

With the conventional tests, the 11 indolepositive, polypectate-positive strains were positive for: the Voges-Proskauer reaction; citrate and malonate utilization; urease; lysine decarboxylase; nitrate reduction; ONPG hydrolysis; gas from glucose; and the fermentation of adonitol, amygdalin (8 strains examined by the API 20 Enteric test only), arabinose, esculin, inositol, lactose, mannitol, melibiose, raffinose, rhamnose, salicin, sorbitol, and sucrose. The 11 strains were negative in the methyl red test, and they produced no gas from lactose at $45 \mathrm{C}$. Negative results were also obtained in the following reactions: hydrogen sulfide production, motility at $37 \mathrm{C}$, arginine dihydrolase, ornithine decarboxylase, phenylalanine deaminase, tryptophan deaminase ( 8 strains examined by the API 20 Enteric test only), lysine deaminase, Tween 80 esterase, Tween 85 lipase, lecithinase, gelatinase, caseinase, DNase, and chitinase. Eight strains fermented dulcitol and two strains hydrolyzed starch. According to Edwards and Ewing (6), these results identify the 11 isolates studied as members of $K$. pneumoniae. Kaluzewski (10) and Stenzel et al. (16) regard indole formation as the key characteristic (Leitcharakteristikum or Hauptkriterium) of the Oxytocum group, to which the 11 strains would thus belong.

\section{DISCUSSION}

Coles (3), who in 1926 reported the formation of acid and gas from pectin by seven strains of Bacterium oxytocum, may have been the first to detect metabolism of polypectate by indolepositive strains of $K$. pneumoniae, and, because they were nonmotile, 19 of 30 strains described by Dias (5) in 1967 as pectinolytic strains of Aerobacter aerogenes may have been indolepositive members of $K$. pneumoniae. Although some workers (4-6) have failed to observe "liquefaction of pectate" by indole-positive strains of $K$. pneumoniae, it is believed that this was due to the method of observation. If, as is suspected, these workers used polypectate medium in tubes (6), the reaction might have appeared as an evaporation of the medium rather than as "liquefaction as with nutrient gelatin medium" (6) and thus may have gone unnoticed. Our observation of the reaction on plates is one of a distinct bowl-shaped depression in the medium beneath and surrounding the patch of growth.

The pectinolytic activity of indole-positive strains of $K$. pneumoniae has several significant ramifications. First, the reaction is developed more rapidly than is the liquefaction of gelatin in stab culture, thus permitting a more rapid identification of isolates as members of the Oxytocum group. The 11 strains studied clearly digest polypectate within $24 \mathrm{~h}$. Secondly, because in the family Enterobacteriaceae the ability to digest polypectate gel is relatively uncommon, this activity may have some taxonomic significance. Kaluzewski (10), with Stenzel et al. (16) concurring, proposed that the name Klebsiella oxytoca should be applied to indole-positive strains, which in all other characteristics are typical for the genus Klebsiella, without respect to their ability to liquefy gelatin. The presently reported observation of pectinolytic activity by indole-positive strains but not by indole-negative strains of Klebsiella lends support to previous proposals $(1,7,8,10$, $11,16)$ that indole-positive strains of $K$. pneumoniae should be placed in a distinct taxon, namely, Klebsiella oxytoca.

\section{ACKNOWLEDGMENTS}

Grateful appreciation is extended to Ned Therien and Sumati Subbaratnam for their technical assistance, to Liselotte Karnish and Barbara Long for their patient secretarial help, and to H. P. R. Seeliger for his advice and suggestions in the preparation of this manuscript.

\section{REPRINT REQUESTS}

Address reprint requests to: Dr. V. Lyle von Riesen, Department of Medical Microbiology, University of Nebraska Medical Center, Omaha, Nebraska 68105.

\section{LITERATURE CITED}

1. Bascomb, S., S. P. Lapage, W. R. Wilcox, and M. A. Curtis. 1971. Numerical classification of the tribe Klebsielleae. J. Gen. Microbiol. 66:279-295.

2. Brown, C., and R. J. Seidler. 1973. Potential pathogens in the environment: Klebsiella pneumoniae, a taxonomic and ecological enigma. Appl. Microbiol. 25:900-904.

3. Coles, H. W. 1926. The digestion of pectin and methylated glucoses by various organisms. Plant Physiol. 1:379-385.

4. Davis, B. R., and W. H. Ewing. 1964. Lipolytic, pectolytic, and alginolytic activities of Enterobacteriaceae. J. Bacteriol. 88:16-19.

5. Dias, F. F. 1967. Isolation of pectinolytic strains of Aerobacter aerogenes. Appl. Microbiol. 15:1512-1513.

6. Edwards, P. R., and W. H. Ewing. 1972. Identification of Enterobacteriaceae, 3rd ed. Burgess Publishing Co., Minneapolis.

7. Hugh, R. 1959. Oxytoca group organisms isolated from the oropharyngeal region. Can. J. Microbiol. 5:251254.

8. Jain, K., K. Radsak, and W. Mannheim. 1974. Differentiation of the Oxytocum group from Klebsiella by deoxyribonucleic acid-deoxyribonucleic acid hybridization. Int. J. Syst. Bacteriol. 24:402-407.

9. Johnson, R., R. R. Colwell, R. Sakazaki, and K. Tamura. 1975. Numerical taxonomy study of the Enterobacteriaceae. Int. J. Syst. Bacteriol. 25:12-37. 
10. Kaluzewski, S. 1957. Taxonomic position of indole-positive strains of Klebsiella. Exp. Med. Microbiol. 19:350-359 (Taksonomiczna pozycja indolododatnich szczepów Klebsiella. Med. Dosw. Microbiol. 19:327335).

11. Lautrop, H. 1956. Gelatin-liquefying Klebsiella strains (Bacterium oxytocum (Flügge)). Acta Pathol. Microbiol. Scand. 39:375-384.

12. MacConkey, A. 1909. Further observations on the differentiation of lactose-fermenting bacilli with special reference to those of intestinal origin. J. Hyg. 9:86103.

13. Paik, G., and M. T. Suggs. 1974. Reagents, stains, and miscellaneous test procedures, p. 930-950. In E. H. Lennette, E. H. Spaulding, and J. P. Truant (ed.), Manual of clinical microbiology, 2nd ed. American Society for Microbiology, Washington, D.C.

14. Seidler, R. J., M. D. Knittel, and C. Brown. 1975. Potential pathogens in the environment: cultural re- actions and nucleic acid studies on Klebsiella pneumoniae from clinical and environmental sources. Appl. Microbiol. 29:819-825.

15. Starr, M. 1947. The causal agent of bacterial root and stem disease of guayule. Phytopathology 37:291-300.

16. Stenzel, W., H. Bürger, and Mannheim. 1972. Zur Systematik und Differentialdiagnostik der KlebsiellaGruppe mit besonderer Berücksichtigung der sogenannten Oxytocum-Typen. Zentralbl. Bakteriol. Parasitenkd. Infektionskr. Hyg. Abt. 1 Orig. Reihe A 219:193-203.

17. Vera, H. D., and M. Dumoff. 1974. Culture media, p. 881-929. In E. H. Lennette, E. H. Spaulding, and J. P. Truant (ed.), Manual of clinical microbiology, 2nd ed. American Society for Microbiology, Washington, D.C.

18. von Riesen, V. L. 1975. Convenient, simplified preparation of less commonly used media. J. Clin. Microbiol. 2:554-555. 